\title{
3. From state to market: regulation of road transport in Australia and South Africa
}

\section{Christopher Walker}

\section{INTRODUCTION}

This chapter examines how a programme of self-regulation initially developed and applied in the Australian trucking sector has been transferred and modified for implementation into South Africa. Drawing on an analysis of documents and an ethnographic methodology that involves participant engagement and observation at industry workshops, attendance at formal agency meetings, site visits and a series of qualitative interviews with key informants, the chapter identifies factors that reshaped the original Australian model as it was implemented in South Africa.

At a descriptive level, this represents a standard study of policy transfer and administrative arrangements from one jurisdiction to another (Dolowitz and Marsh, 1996). However, at a more fundamental level, it provides several original insights for policy transfer research. First, in contrast to the traditional focus of research in this field, the countries involved in this study allow us to observe policy transfer that goes beyond the boundaries of developed Western democracies. Here we see transfer that is more typical of a north-to-south process as policy devised in a developed economy is transferred to a developing one. Second, we see policy transfer that is characterised by state-to-market processes rather than the more common state-to-state transmission documented in the transfer literature (Bennett, 1991; Benson and Jordan, 2011; Rose, 2000). Finally, this study shows how a detailed micro-level analysis of policy transfer identifies innovation and modifications developed during implementation that may in turn present possible policy improvements for the originating jurisdiction. New ideas and lesson-drawing from abroad can contribute to a broader policy cycle that might include 
feedback to the originating jurisdiction where the policy was first initiated. Thus, notions of feedback and adjustment in the popularised concept of the policy cycle (Howlett and Ramesh, 1995) shift from an analysis of local practice in one jurisdiction to an expanded model that considers innovations developed through international policy transfer.

This chapter is organised into the following sections. First, discussion provides an overview of the analytical approach and how it aligns with aspects of the policy transfer literature and what key questions will be addressed in this study. This is followed by the background and policy context that shaped the development of the regulatory policy programmes in the two countries. This includes a comparative analysis of how each regulatory programme works, where they differ and an outline of their general compliance objectives. This leads to a more detailed analysis of the transfer case, drawing on qualitative data to identify key factors that shaped policy and regulatory adaptation in South Africa. The final section further explores the concept of state-to-market transfer and considers how lesson-learning can continue through feedback mechanisms to the originating jurisdiction.

\section{TRANSFER, ADAPTATION AND INSIGHTS FROM THE PROCESS}

When mapping out the transfer literature, the introductory chapter of this volume identified seven distinctive pathways for understanding and analysing the phenomenon of policy transfer. The case presented in this chapter aligns with the largely rational and technocratic approach to the study of policy transfer with a strong conceptual concern for diffusion, learning and policy transfer (Dolowitz and Marsh, 1996, 2000; Rose, 2000). Under this approach the focus of analysis is concerned with the role of actors and key institutions as well as the specifics of the policy being transferred. Understanding processes of actor engagement and the dynamics of the policy process are important for mapping policy and regulatory development. Adopting this lens of analysis shifts the inquiry towards the way policy is modified during implementation and factors that may have influenced those modifications.

While policy transfer may occur within a domestic context between levels of government (see for example the chapter in this volume by Mavrot), it is within the international context that the process appears more directly exposed to factors that influence modification and implementation. This includes language, culture, constitutional system, geographical proximity, economic structure and resources (Marsden and 
Stead, 2010). The literature notes that domestic context is often critical in determining the success of policy transfer (Swainson and de Loe, 2011). Clavier posits that policy transfer is more likely to be successful if those ideas being transferred 'fit with domestic institutions, representations of policy and political issues and if they provide (partial) solutions to these domestic issues' (2010: 453). This is supported by De Jong and Geerlings who observe that it is widely believed that 'transplantation of policy models between countries with similar legal, cultural and institutional characteristics, is easier', so long as 'subtle institutional differences and practical policy problems' in the receiving state are recognised and addressed (2005: 181). These observations on likeness help explain why much of the literature documents the success of policy transfer in a Western context. In response to this, there have been calls for the analytical focus to move away from an 'excessive preoccupation with Western countries' (Marsh and Sharman, 2009: 270; Marsden and Stead, 2010). This chapter addresses this deficiency in the policy transfer literature and provides a micro-analysis of policy transfer between states marked by significant domestic and cultural differences. The investigation also highlights how markets play an important role in adjusting for differences in state capacity, a unique process identified in this chapter as state-to-market policy transfer.

This chapter also addresses the central questions identified by Dolowitz and Marsh (2000) to understanding policy transfer. This includes identifying who the key actors are in progressing policy transfer and their reasons for being involved, what factors influence what is transferred and how the original policy has been reshaped for local adaptation. These questions focus the investigation towards different elements and stages of the transfer process, including early recognition of the need for policy, mechanisms of learning involved in the development and implementation of policy, and the influence of resource and institutional capacities (Evans, 2009a).

Finally, before moving to a detailed discussion of the case, it should be noted that the chapter also addresses a criticism by Evans that "policy transfer analysts fail to make their research relevant to the world of practice' (2009b: 238). Drawing on our findings, we suggest an additional stage that might be included in the transfer of policy. It would involve identifying lessons learned in the transfer process that can contribute to the ongoing development of policy and programmes across global domains. How can lessons learned and developed in the adopting jurisdiction be transferred back to the home jurisdiction? Is there evidence of feedback across states? It is important for policy makers to remain aware of international developments in policy transfer since 
lessons from practice, improvements and refinements may increasingly emerge from the global process of transfer and adaptation, just as much as they do from domestic processes of formal evaluation and review. This chapter proposes that lessons learned in the context of resourceconstrained developing countries may represent significant improvements and insights into policy practice. Before presenting the evidence and reflecting on the above questions the following discussion provides an overview of the policy context and the regulatory policy programmes under review.

\section{THE POLICY AND REGULATORY CONTEXT}

Trucking is a highly visible industry that relies on continuous access and utilisation of the road network. While trucking fleets in most economies represent a relatively small proportion of the total vehicles that use the road system (around 3 per cent), the industry's impact on the road network is significant in terms of wear and tear, congestion and safety. Poorly maintained vehicles are regularly associated with breakdowns and have a major impact on congestion and road network efficiency. Similarly, overloaded vehicles excessively degrade infrastructure and pose safety risks to other road users, while drivers who work excessive hours and are fatigued are more likely to lose concentration and react poorly in urgent situations, causing accidents. In a number of countries the permitted length of trucks and the total weight of goods they can carry has incrementally increased over time and these larger, heavier vehicles, when involved in incidents, tend to result in major disasters resulting in significant network disruption (Walker, 2012). When compared to other industries, trucking is notably unsafe. In Australia the trucking industry has the highest rate of compensated fatalities across all industries (NTC et al., 2008; Safe Work Australia, 2015). The situation is similar in the US and UK where road transport is the leading source of workrelated fatalities (Poulter et al., 2008; Newnam and Watson, 2011; Spielholz et al., 2008). In South Africa the trucking industry has a very poor safety record with a fatality rate that is seven times the rate in Australia (OECD, 2011: 176). Evidence on the safety performance of the industry throughout the world clearly suggests there is need for improvement.

A range of issues contribute to the industry's poor safety performance. However, vehicle maintenance, the accuracy of vehicle loading and effective management of driver fatigue, driver health and driving hours are known to be critical factors that affect safety performance. The safe 
transport of goods, the efficient operation of the road network, and strategies that help ensure the sustainability of infrastructure are central concerns of road transport agencies. As a result, governments around the world have responded with various policies and programmes to improve the compliance and safety performance of the trucking industry. This has included targeted inspections, roadside enforcement strategies, prescriptive regulation, practice guides for industry, and voluntary improvement programmes.

In Australia, one response to these policy challenges has been the introduction of the National Heavy Vehicle Accreditation Scheme (NHVAS). It was introduced in 1999 with clear objectives to increase the levels of legal compliance across the industry, reduce vehicle overloading and associated infrastructure damage, and subsequently improve the safety performance of truck operators (NRTC, 1998). Reviews of the programme have revealed that firms registered under the scheme do have better safety records than those who are not (Baas, 2008). The success of the NHVAS has appeal to other governments that face similar challenges in the road transport and trucking sector. During the early 2000s South African officials were examining ways to reduce truck overloading and improve the safety performance of their industry (Steyne et al., 2004). Their research identified the Australian programme as a possible policy initiative worth adopting. Over time, following close interaction between industry and government officials from both countries, a modified version of the scheme was introduced into South Africa under the title of the Road Transport Management System (RTMS). Details on how each scheme works is outlined in the next section; however, for now it is worth noting that both schemes share similar objectives targeting industry safety and road infrastructure protection.

Both the Australian and South African schemes adopt a framework of voluntary self-regulation, though each varies in the manner in which it is managed at the national level and the extent to which it draws on state and industry authority. The structure and operation of each scheme is consistent with the features of a standard voluntary self-regulating compliance programme, in particular, the articulation of specified standards that must be met before accreditation is granted. Under each scheme an auditor reviews and confirms compliance with standards. Entry to the scheme is then granted and an appropriate label/placard, which is fixed to trucks of the fleet, is issued to the operator. The label both advertises the accreditation status of fleet vehicles and also facilitates discretion at enforcement sites. Under the schemes, accredited vehicles may be eligible for some form of regulatory concession or wave-through at inspection points. While similar, each scheme has distinct operational 
characteristics. These characteristics have emerged from the transfer and adjustment process as the Australian programme was reshaped for implementation in South Africa. The differences centre around the role of state agencies in supporting the operation of the scheme, the role of market forces and market participants in furthering the compliance initiatives of the scheme, and the particular focus of each scheme on aspects of business practice and managing risk in trucking firms. The following discussion outlines the key operational features of each scheme, highlighting areas of difference.

\section{AUSTRALIA: THE NATIONAL HEAVY VEHICLE ACCREDITATION SCHEME (NHVAS)}

The NHVAS is organised and administered through a national regulatory agency, the National Heavy Vehicle Regulator (NHVR). In contrast to standard regulatory programmes that make use of punitive enforcement, the NHVAS draws on a different range of incentives and strategies to engage industry. Most notable is that the programme is voluntary and consists of three modules that specifically target safety and compliance concerns around vehicle maintenance, vehicle loading and the management of driving hours. The scheme requires operators to meet higher standards in compliance practice than those specified in the general regulations that govern the industry in these areas. By demonstrating that they maintain record systems, have maintenance, checking and review processes that are continuous, rigorous and effectively manage compliance risks, truck operators are then permitted to operate at levels that extend beyond the normal regulated limits. For example, operators who demonstrate they meet the operational standards of the scheme, maintain robust record keeping, management and review practices for vehicle loading (known as the Mass Management module) and undertake corrective action where errors are detected, are allowed to carry weights that are up to three tonnes above the general regulated limits (NHVR, 2015). This is considered a significant productivity advantage by the industry. Similar regulatory concessions are offered for vehicle maintenance (no mandatory annual vehicle inspection) and driving hours (options for drivers to drive additional hours in certain circumstances). The logic is that these concessions on regulatory limits help provide a competitive edge and commercial gain for truck operators who are prepared to demonstrate higher levels of compliance and therefore help assure the regulator that risks are being effectively managed (NTC, 2008). 
The Australian national trucking regulator, NHVR, manages a list of approved auditors that firms may engage to assess their management and documentary systems. It is these external auditors who measure and verify performance and practice against the audit matrix issued by the regulator. These standards are periodically reviewed to help strengthen and enhance the integrity of the scheme (NHVR, 2013; NTC, 2015). Once management control systems are verified to match scheme requirements, the auditor completes a compliance report that is forwarded to the NHVR. Approved and registered operators can then access the regulatory concessions associated with the module of enrolment and as a result of the placard/sticker displayed on the vehicle, are likely to be subject to less roadside stops and inspections.

To help maintain commitment to the scheme and reduce manipulation and deception, the NHVR commissions random audits of firms to help validate and police ongoing compliance to scheme standards. The scheme is characteristic of responsive regulatory practice (Ayres and Braithwaite, 1992) where there is a stronger focus on educative engagement with industry rather than punitive enforcement and the immediate issue of fines. The scheme is popular amongst the Australian trucking industry with around 90000 vehicles enrolled in the programme (approximately 7200 transport fleets) and the NHVR reports that since 2012 there has been annual growth of 10 per cent in enrolments (NHVR, 2014).

As a regulatory programme the NHVAS applies a unique set of compliance tools (economic incentives) that have reshaped engagement with industry around operational standards, safety, compliance and enforcement. The scheme draws on the private resources of firms (and auditors) to assist in the assessment and validation of compliance. In addition, the scheme allows enforcement agencies to be more strategic with the deployment of inspection resources, for example, at roadside inspection sites officers can filter out NHVAS firms since they are expected to be compliant with regulatory standards. Regulators and industry associations support the scheme, arguing it is an effective supplement to prescriptive enforcement (Baas, 2008; Walker, 2012).

\section{SOUTH AFRICA: THE RTMS}

The RTMS differs from the NHVAS in the way its governance is organised and the manner in which the scheme is funded and managed. The RTMS is managed through a national steering committee that draws on a broad base of industry representation and government agencies. This includes voluntary representation from national and provincial road 
agencies, the national industrial research institute (Council for Scientific and Industrial Research, CSIR - see http://www.csir.co.za/index.html, accessed 14 April 2016), truck industry associations, major trucking industry operators, representatives of consignors, the banking and finance industry, the insurance industry and representation from the truck sales and manufacturing industry. While national and provincial road transport agencies support the programme, state financial resources are not provided to fund its administration. However, it should be noted that the CSIR is a major advocate for the scheme and heavily involved in supporting the voluntary effort of industry participants. The RTMS is essentially an industry-operated self-regulation scheme where voluntary effort and membership fees are expected to cover the operational costs and administration of the scheme. This is in stark contrast to the NHVAS, which is fully funded by the national regulator and the notional membership fees do not cover operating costs (Walker, 2015). The RTMS steering committee meets regularly and oversees the development of standards and other operational matters. The steering committee supports a rolling programme of workshops across South Africa that engages provincial road agencies, local trucking and business associations, and local truck industry participants. These workshops explain how the scheme works, promote the benefits of the RTMS through industry case studies, and aim to encourage and recruit membership.

The RTMS steering committee has engaged one private auditor to assess applications. This operational aspect of the scheme is consistent with the NHVAS. An external auditor reviews the firms with respect to their management practices, documentation and compliance to programme standards. Firms assessed as meeting the required standards pay a fee and then are admitted and registered under the RTMS. However, unlike the NHVAS, the RTMS does not offer separate modules that operators can opt to join. The RTMS requires a whole-of-business approach, and to enter the programme, truck operators must demonstrate a capacity to meet all specified standards under the programme.

Scheme standards cover a broad base of trucking activities. The standards have been registered and published through the South African Bureau of Standards (SABS) (https://www.sabs.co.za, accessed 14 April 2016). The standards cover driver wellness (diet, rest, HIV prevention and testing, management of driving hours and vehicle scheduling), vehicle loading, vehicle operations (including maintenance, driver training and fleet management), and business productivity (record keeping and other important business practices) (Nordengen and Pienaar, 2007). Scheme standards have a strong focus on improving operational safety but also contribute to business efficiency and business practices, which is 
a feature derived from broader national policies regarding black empowerment and supporting local businesses.

Unlike the Australian scheme, the RTMS does not entitle operators to regulatory concessions, though provincial governments have used membership of the RTMS as a requirement for approval to operate certain nonstandard truck configurations, such as over-length car carriers. Scheme members are also likely to obtain a 'wave through' at routine inspection points. Unlike the NHVAS, the scheme also contains standards that apply to consignors and consignees about the manner in which they engage with road transport operators. The scheme seeks to engage firms involved in the transport chain that can have an impact on road safety, infrastructure maintenance and the productivity of the logistics chain, particularly through the manner in which they contract with trucking firms. For example, provincial road agencies and the RTMS steering committee have worked closely with coal, timber and sugar cane industries where consignors and receivers have sought to address safety and infrastructure concerns, such as excessive road wear through overloading and accidents associated with vehicle stability and poor maintenance (RTMS, 2016). The contracting framework and the behaviour of receiving depots (such as refusing to accept overloaded vehicles) can have a significant impact on the compliance practices of trucking firms. So, in contrast to the specific and narrow operator focus of the NHVAS, the RTMS has a broader level of application and relevance to organisations engaged with road transport businesses. A comparative summary of the features specific to each scheme is presented in Table 3.1.

There are approximately 146 certified companies operating under the RTMS and this represents approximately 8000 vehicles (RTMS, 2016). The scheme is both younger, commencing in 2003, and smaller than the NHVAS. Industry associations and road agencies are supportive of the RTMS and informed participants believe the programme is effective in improving safety and compliance in the trucking industry. The evidence collected from long-term (two years) trials in the coal, timber and sugar cane industry demonstrates that loading compliance has improved and the record of accidents and injury has declined over the period of the trials (see published results at http://www.rtms-sa.org/product/successstories, accessed 14 April 2016). 


\section{Table 3.1 Comparative summary of key features}

\begin{tabular}{lll} 
Feature & $\begin{array}{l}\text { Australia-National Heavy } \\
\text { Vehicle Accreditation Scheme } \\
\text { (NHVAS) }\end{array}$ & $\begin{array}{l}\text { South Africa-Road Transport } \\
\text { Management System (RTMS) }\end{array}$ \\
\hline Administration & $\begin{array}{l}\text { State agency-National Heavy } \\
\text { Vehicle Regulator (NHVR). }\end{array}$ & $\begin{array}{l}\text { Voluntary national steering committee } \\
\text {-broad industry and government } \\
\text { representation. }\end{array}$
\end{tabular}

Standards
authorisation

Suite of standards

Assessment of compliance and eligibility

Scheme funding and membership fees

Participation

Links with regulatory concessions and requirements

Compliance and enforcement
Business rules and compliance requirements published by national regulator (NHVR). Linked to formal regulatory framework to permit exemptions and concessions.

Three specific modules: Mass management, Maintenance management and Fatigue management. Operators may opt for one, two or all three.

Approved auditors assess firm procedures, systems and documentation against scheme standards. Operator pays for audit. Auditor submits report to regulator. Renewal audit required on 2-year cycle.

State funding supports scheme. Membership fees designed not to be barrier to entry.

Voluntary - 7200 fleet operators/ 90000 vehicles. $35 \%$ of all articulated vehicles.

Entitled to carry extra mass, exemption from annual inspections, eligibility to drive longer hours, wave through at inspection sites.

Strong reliance on state inspectors. Check compliance at roadside and through random audits.
Approved through national standards body (SABS). Not directly linked to road transport regulation.

Holistic approach to management and operation of business. Safety, driver wellness, maintenance, loading, scheduling, driver training, fleet management and business productivity. No options, must meet full suite of standards.

One approved auditor assesses firm procedures, systems and documentation against scheme standards. Operator pays for audit. Audit report submitted to steering committee. Renewal audit required on 2-year cycle.

Fee revenue expected to meet operational costs of scheme. Voluntary commitment of industry and government members of steering committee ensure ongoing operation of scheme.

Voluntary - 146 fleet operators, mostly large firms -8000 vehicles. $30 \%$ of members have 10 or less vehicles.

Provincial discretion, e.g., extra long car carriers - KwaZulu Natal Requirement for Performance Based Standards approval.

Strong reliance on markets. Industry monitored and compliance incentivised through markets, e.g., banks, consignors, receivers. No state enforcement. 


\begin{tabular}{lll}
\hline Evidence of & No published data on compliance & Evidence collected from trials with \\
success & performance. Studies suggest & coal, timber and sugar cane industries \\
& lower crash rates and safer & - load compliance, accident/injury \\
operators (Baas, 2008; Walker, & rate. Data published on RTMS website \\
2012). Effective in building & http://www.rtms-sa.org/ \\
industry-regulator relations. & product/success-stories. \\
\hline
\end{tabular}

A central question for this study is what brought about the distinctive differences between the NHVAS and RTMS. It is evident from the data presented in Table 3.1 that both schemes share similar objectives, yet their modes of governance and operational structure have developed along different paths. As mentioned at the beginning of this chapter, the author adopted a qualitative approach when inquiring about and analysing the case. This involved interviewing all members of the RTMS steering committee, attending stakeholder workshops and meetings, undertaking field visits and engaging in discussions with a wide group of interested actors. Observing different settings (formal and informal interactions) has provided insight to the key issues that have shaped interest in Australian road transport policy, processes of transfer and adaptation, and stakeholder responses to the newly developed model of self-regulation (RTMS) implemented in South Africa. The following discussion draws on the evidence and findings of this interaction and addresses the key questions outlined at the beginning of this chapter. Discussion considers key actors involved in the transfer process and the role of international networks. The influence of domestic and international economic pressure is also considered. A key challenge for the implementation of the RTMS has been how to deal with state corruption. The evidence presented below shows that this concern pushed policy design towards an industry-based model that relies on the guidance of a steering committee, consisting of representatives from all the major stakeholders. The collaborative governance structure reflected in the RTMS steering committee allowed standards and organisational processes that structure the scheme to emerge from observations and lessons gained from industry trials. These trials focused on particular policy concerns to both industry and government; concerns such as, how to prevent overloading and better ways to manage driver health. Finally, the evidence presented in the following section notes how innovative the South African framework is in drawing on market players and economic forces to influence the compliance of trucking firms. This policy adaptation is both a response to resource constraints and a desire to minimise exposure to potential state corruption. 


\section{THE CASE AND RELEVANT FINDINGS}

\section{Who is Involved and Why? International Networks and the Development of the RTMS}

International engagement, the exchange of information between regulatory and policy officials, and the development of networks of relationships between road agency officials from South Africa and Australia have been instrumental in facilitating the development and implementation of the RTMS. The willingness of South African road agencies and industry associations to consider the introduction of some form of supplementary self-regulation has also been influenced by broader contextual factors that have shaped thinking and preferences about the relationship between the state and markets. This includes the global diffusion of neoliberalism and NPM ideals (O’Flynn, 2007; Pollitt, 2007; Schmidt and Thatcher, 2013), the convergence of this thinking with the emerging constraint on public sector budgets and agency resources, and a growing body of reports and evidence that suggests models of industry self-regulation can supplement prescriptive regulation and enforcement (OECD, 2002, 2010). Within this context, the key challenge for interested parties has been around how to reshape the operational detail of the highly state-directed Australian NHVAS programme into something that would work in the South African context.

Australian and South African officials have been actively engaged in the exchange of information and ideas since the early 2000s, and this has supported a process of learning and development with regard to policy design and regulatory standards. There was a series of visits in 2003, 2004, 2005, 2010 and 2013 by senior staff from South African road agencies, research institutes and industry representatives to the Australian road transport regulator (the National Road Transport Commission, NRTC) and state road agencies. These visits were initiated in response to local policy reviews and inquiries that sought to find ways to improve road safety and minimise truck overloading across South Africa. One such report specifically recommended that South Africa consider the introduction of a compliance programme along the lines of the Australian programme (Steyne et al., 2004). Visits and exchanges also occurred with Australian research institutes (Australian Road Research Board), industry associations, major transport companies, and key consultants working in the sector. These visits helped sustain relationships between agencies and officials and facilitated an ongoing dialogue around policy and regulation. In addition to these visits, officials, academics, consultants and 
industry representatives from both countries interacted and reported on regulatory innovations and practice at major international conferences and forums that explored industry safety, vehicle innovation and regulatory practice. Of particular importance was the International Forum for Road Transport Technology that is held on a bi-annual basis and has had regular attendees and presenters from Australia and South Africa, often the same officials who had met during visiting delegations (Nordengen and Oberholtzer, 2006, 2007; McIntyre, 2005; Moore, 2007a, 2007b; Potter, 2010). Through these interactions a number of leading South African and Australian officials developed collaborative partnerships and subsequently worked on international research projects commissioned by the OECD International Transport Forum (International Transport Forum, 2014). A recent example was a comprehensive multinational study on heavy vehicle safety and productivity (OECD, 2011). This process of liaison, interaction and the exchange of ideas helped sustain relationships, allowing South African stakeholders to readily draw on documentation and advice from the Australian road transport industry and regulatory agencies in the development and implementation of the RTMS.

\section{International Influence}

While senior bureaucrats and experts cultivated an epistemic community of interest around models of self-regulation, they were further exposed to international influences through funding and trade arrangements. These forces have been influential in shaping and sustaining interest in a programme that would help improve transport safety. One interviewee claimed that international funding in transport infrastructure was influenced by the views of G8 (Group of Eight industrial democracies) countries, 'There is definitely a push from the G8 to get better safety and more efficient systems in place' (Interviewee 2, hereafter I2). Other industry participants cited international influence through trading arrangements, observing, 'a lot of our European and American clients are now starting to demand confirmation to EU standards ... RTMS addresses driver welfare and so it is becoming more and more of a criteria out of our European clients' (I5). This same interviewee noted that it was the international influences rather than government that were effective in influencing industry behaviour and their interest in supporting a programme such as the RTMS, 'it's the international influences ... It is not driven by government' (I5). These observations reveal how broader economic and social forces generate demand and build interest in 
the transfer and adoption of policy concepts that address particular domestic problems.

\section{Factors that Influence what is Transferred and Shape Local Adaptation}

Four key factors have shaped stakeholder interest in the development of a regulatory programme such as the RTMS. The first derives from both perceptions and the experience of weak and corrupt practices with regard to regulation and enforcement across the trucking sector. During discussions with key informants, most felt that the regulatory framework for the trucking industry was well designed and legally robust. However, the level and quality of on-road enforcement was seen as inadequate and corrupt. This represents a key challenge for the sector, one that has been acknowledged for some time (Jankauskaite et al., 2013). Interviewees were critical of the capability of enforcement staff, 'they don't have a basic understanding of what is legal' (I1). This was echoed by another respondent who stated, 'There are too many regulations ... half of them the guys don't even know they exist and they're inadequately policed' (I5). One industry respondent argued that enforcement organisations 'have a huge skills shortage and need basic education' (I8). Another interviewee claimed that 'a lot of effort goes into regulation but the technical competence of law enforcement officials is not there' (I9).

Others observe that where enforcement is stringent this appears to be driven by interest in corruption. As one interviewee observed, 'my experience of the regulatory enforcement is that it's overzealously applied in certain areas, but not necessarily for the purpose of regulatory enforcement, more as a coercive measure to extort bribes from operators' (I3). Another interviewee observed that 'Corruption has undermined the whole road freight compliance scenario' (I4). Corruption was seen to shape both the practices of enforcement staff and operators, as one industry representative commented, 'Bribery and corruption are absolutely rife, so people don't budget for fines they budget for bribes' (I8).

The interview data suggest that the failure of the state to effectively implement and deliver a stable and fair enforcement regime was a key reason why many stakeholders favoured the introduction of an alternative programme of voluntary self-regulation, like the RTMS. Perceptions that standards of safety have declined encouraged industry to step in and take action on the issue. 'So now we have something that is being driven by the industry ... government is just not there. They're just not visible' (I7). Another interviewee claimed it was the concern of major consignors who saw the need for better regulation that was behind the start of the RTMS. 
He explained, 'it was safety issues in terms of their risks and it was the premature degradation of the road network that was affecting their business in terms of productivity and costs' (I9). The evidence from stakeholders identifies industry as a major actor pushing for regulatory reform and by doing so creating an opportunity for policy transfer. A key challenge for local policy agents was how to adopt the predominantly state-centred model operating in Australia to an environment where interest was primarily driven by industry. How this was achieved is discussed in more detail below.

A second influential factor that shaped stakeholder interest in the adoption of the RTMS concerned the growing interest in raising industry compliance standards and building better relations with government. While the Australian and South African models of industry selfregulation share a common interest in voluntary participation, a notable difference is the South African preference to retain a perceptible level of independence from government. Industry enthusiasm for a voluntary programme, combined with the resource and capability constraints faced by road agencies in South Africa, saw the RTMS develop significantly different governance and funding arrangements. Industry saw selfregulation under the RTMS as a way of achieving rigorous and credible standards of compliance that are less exposed to government intervention and possible corruption. One interviewee noted, 'they've seen that there's not a single cop involved, no corruption, and it's starting to make inroads into their thinking. It's starting to draw interest. They accept this as a trucker's program not a government thing' (I5).

While wanting to operate with independence from the delivery arm of government agencies, industry stakeholders also recognised the importance of engagement with senior state officials and the symbolic value of government policy support. Government support is seen as critical in sustaining and building the RTMS across the sector since this can also lend credibility and legitimacy to the scheme. While relatively straightforward in the Australian context, the challenges to ethical and rigorous governance in the South African context made it difficult to get the balance right. Industry wanted government support and endorsement but not direct government involvement because of concerns with both competence and corruption at the delivery and implementation level. As one interviewee commented, 'You know, everything that the government gets its hands on, it ends up in a huge bureaucracy and nothing actually functions. The national government sees these initiatives, takes them into the national framework and they just fall apart, they disappear' (I8). 
These concerns were central in reshaping the Australian policy model and seeing governance structured through a steering committee framework that draws on all interested stakeholders as members and contributors. To a significant degree the RTMS steering committee framework provides an effective forum for engagement between representatives of government and industry in which policy support can be achieved while maintaining some independence from the direct involvement of agency and enforcement staff. As noted earlier, steering committee membership consists of a broad base of stakeholders from government, industry and broader interested parties such as consigners/consignees, insurance and banking. Committee members volunteer their time and work for the RTMS steering committee, though a significant level of secretariat support is provided through the national research institute (CSIR). This model of management is distinctly different from the Australian approach, which relies on direct management of the programme through a national regulatory agency with no advisory committee or forum for industry input.

An interesting outcome of the modified governance structure adopted under the RTMS is that the scheme is seen to improve relations between industry and government and enforcement authorities. Here we see how industry recognises the value in having a better relationship with government and how the RTMS is seen as 'an important tool ... to help us improve the relationship between transporter and authority' (I2). This recognition is further evident in the mutual interest of both industry and government for the protection of infrastructure. By providing a means to enforce better road asset management, the RTMS has sustained government attention and interest and this has in turn provided an opportunity for government-industry relations to improve.

Learning through trials and practice has been another influential factor in the transfer and implementation of the RTMS. Much of this activity has come about with state support primarily through the lead champion of the programme, the CSIR. The enthusiasm of CSIR has been matched by proactive provincial governments that have significant primary industries that rely on the road transport of heavy goods such as grain, timber and minerals. In these regions the state has a major investment in road infrastructure (KwaZulu Natal for example). Mutual interests in the protection of infrastructure and improved road safety have seen the development of collaborative trials between government road agencies, primary industry (coal mining, timber and sugar cane) and road transport operators. Many of the participants in these trials had previously sent representatives, as part of the official delegations that visited Australia, to observe how the NHVAS policy and regulatory programme operated. The 
combination of international observations and local trials has been instrumental in assisting the development and implementation of RTMS standards. Here, active engagement between stakeholders with shared interests has helped facilitate the transfer, adaptation and implementation of the RTMS policy in South Africa.

Finally, the fourth factor that has significantly shaped local adaptation of the Australian concept has been the innovative use of market incentives to help direct industry interest towards better compliance practice. In the absence of a strong state presence to effectively influence industry compliance, the architects of the RTMS have been very creative in drawing on market factors that can shape truck operator behaviour. The broad industry membership of the RTMS steering committee provided opportunities for new insights into how market instruments could be used to influence safety and operator compliance. While remaining an essentially voluntary and self-regulatory programme, industry actors see the RTMS expanding through the sector where it is pushed by other important market participants, such as major consignors and large hauliers. These firms can directly influence the uptake of the RTMS by specifying membership as a requirement in contracts with trucking firms. One industry representative saw this as the primary way of reaching a 'tipping point, a critical mass' (I2). And another industry representative observed, 'if you ensure that the person receiving the load or consigning the load has a role to play ... then, yes, I think you could actually have a marked impact on regulatory non-compliance' (I3). And this is seen as a good outcome. 'So it is forced down by private industry, by the private sector. Not the government ... so it still keeps its credibility' (I1). The evidence suggests that for trucking operators the use of market instruments and power to direct behaviour is more acceptable than intervention by government.

The theme of business pressures directing the take up of the RTMS was common across a number of interviewees. Another industry representative stated that pressure and requirements from consignors and consignees were important for expanding the take up of the RTMS, 'without detracting from the voluntary aspect of it, it becomes a business decision. It is not a government forced decision, it's a business decision you take if you want to operate in that business' (I6). Under these arrangements consigners and large firms were then able to push the requirement to join the RTMS onto smaller trucking firms. These comments show that industry participants find market factors that shape business decision-making as effective and acceptable agents of change. There appears to be general support for the use of business power to 
force trucking firms to change operational practice and comply with the standards specified under the RTMS.

These discussions also reveal the close association between effective business practice, profitability, safety and regulatory structures. Industry and business representatives on the RTMS steering committee see regulation and specified operational standards as playing an important role in shaping markets, managing risk and improving safety. This was particularly evident in discussions with committee members from the banking and insurance industries. For these industries, the unregulated nature of the trucking industry, the limited level of effective government oversight, and the poor safety performance of operators make the industry a high business risk. Better self-regulation under the RTMS was seen to make business in the sector more viable. As an insurance representative noted:

We are actually hesitant to get involved in this specialised area ... what RTMS brings to the whole industry is a bit of regulation which controls risk, encourages risk management ... this allows insurers to get involved a little bit more ... It is about being able to take a transporter and make him insurable.

The interview evidence shows how the RTMS adds to the commercial gains of industries that extend beyond truck operators. In the following quote the bank industry representative explains how the RTMS documentation requirements also serve as risk management tools for their clients:

funding of their trucks is dependent on RTMS accreditation and maintaining it. And what is quite nice about RTMS is that every quarter the firm has to update their compliance information. I get permission from the customer and I get the full audit reports on line. It deals with everything from contracts, drivers, procedures ... It's fantastic. I can see how the firm is going. Are they a good customer or risk for the bank?

The preceding evidence shows how other stakeholders share the RTMS goals of safety, security and driver well-being since performance in these areas also relates to business viability and profitability. As one industry observer noted, 'The only way we are going to have the transport industry really profitable, safe, fundable, bankable, is by industry taking a stance and taking on some form of self-regulation, like RTMS' (I7). This is particularly important in the South African context since statebased regulation is known to be exposed to corruption and therefore 
considered a less reliable force for managing industrial risk and stabilising the market by enforcing fair competition. The RTMS approach to incentivising membership is distinctly different from the Australian approach under the NHVAS. While the Australian model also uses market incentives to shape truck operator behaviour, the influence derives from the productivity gains available from regulatory concessions rather than the power that can be exercised by other important market players to influence firm-level decision-making. The South African experience shows that there are valuable lessons around the role of market forces in shaping truck operator compliance that can be fed back to Australian policy makers and possibly included to strengthen compliance with the NHVAS.

\section{STATE-TO-MARKET TRANSFER}

This chapter set out to examine who is involved in policy transfer, why actors engage in policy transfer, and what factors influence the transfer process and shape local adaptation. Interest in these questions stems from a hope that a deeper examination of policy transfer and approaches to adaptation may reveal ongoing innovations that can be fed back into the global network of policy exchange and facilitate improvements in originating jurisdictions. In this study we have seen innovations that draw on a wider engagement of interested industry parties to make effective use of market incentives to shape attitudes and behaviour towards compliance practice and regulatory standards. The end result is a state-derived model of voluntary self-regulation that has been redesigned and implemented with a foundation that is directly linked to significant industry and market stakeholders. This reflects a model of policy and regulatory governance that accepts a diminished role for state actors. Unlike traditional notions of state-to-state policy transfer, the different organisational and cultural contexts of transfer have delivered innovations that characterise this process as state-to-market. In this case study we see policy transfer reshape a predominantly state-centred approach towards regulation and compliance into one that has a dominant market-centred approach.

The micro-analysis of this transfer case reveals the integration of market interests and public policy goals shaping private regulatory practice. By extending market interests into the voluntary self-regulation programme, the RTMS is able to draw on a broader range of incentives that shape compliance. This has been effectively achieved through the multi-stakeholder governance structure of the RTMS and the relative autonomy the programme has from government enforcement agencies. 
Under the RTMS, business interests act in a manner that pushes policy goals normally pursued and enforced by the state. In contrast, the Australian approach to self-regulation has not directly drawn on these broader market incentives, since the NHVAS is predominantly shaped from a regulator's perspective and makes use of regulatory tools, direct enforcement and fear of random audits to influence industry behaviour.

What we also observe in this case study is evidence of market evolution where norms of restraint are developed and sanctioned by market participants themselves (Abolafia, 2001). In the South African context, weak and corrupt enforcement has the potential to undermine market legitimacy. In response, dominant market players occupy this space in adopting and promoting governance norms that ensure the ongoing viability of a fairer market. The key instrument here is ensuring operator enrolment in the RTMS. This action appeals to domestic interests and is particularly important where market participants have links and connections with a broader global market that tends to reinforce standards and practices to a minimum global norm (Peck et al., 2012). The RTMS therefore appeals to key actors in both the domestic and international market. Here we see states and industry maintaining and practising a level of interconnectedness that both transforms markets and helps promote competitiveness at a global level (Cerny, 2010: 6). In this case study, important state and market policy actors have played a role in connecting at the local and global level so they can effectively act to reshape regulations and markets to help manage risk and protect industry profitability.

This transfer case also shows that models of self-regulation are adaptive to local environments and the nature of incentives that shape industry participation reflects a calibration of state and market influences. Effective self-regulation can be shaped by strong state engagement and, as seen in Australia, can use the power of state authority to moderate regulatory limits to incentivise membership and deploy enforcement resources to monitor ongoing compliance. What is of interest in the South African case is that where the state is unable to deliver a consistent regulatory framework, industry leaders are prepared to deliver the 'regulatory effect' through other mechanisms based on self-regulation. The South African case raises questions about the extent to which regulatory effort can be state-led or industry-led. In the South African case, strong calls are made on powerful industry participants to align the compliance of firms with specified standards that represent an agreed framework of operational and regulatory standards that supports the effective management of business risk and helps sustain the profitability of related market players, such as banks. This then raises questions about how market 
power and authority might be organised and exercised to deliver an effective regime of compliance, and the extent to which this aligns with broader public policy goals of infrastructure protection and on-road safety. These are important questions for further research and extend beyond this study. Nevertheless, what is of consequence from this work is the recognition that policy transfer may involve adjustments that recalibrate the relative role of the state and non-state actors in managing and delivering the policy effect. It should be noted that the potential for state-to-market policy transfer may be a phenomenon more evident, particularly in the regulation of industries, as we move towards an increasingly globalised and neoliberal world.

\section{INNOVATIONS AND FEEDBACK INTO THE GLOBAL POLICY NETWORK}

In this case study, international engagement has been a major factor in facilitating learning and supporting the transfer of policy. The desire to learn how to do things better appears to have also been driven by domestic and global pressures to increase the safety, efficiency and competitiveness of markets. The case illustrates how the interaction of global pressures, domestic strategies and institutional capabilities orientates policy agents towards learning and inquiry as they examine how external policy innovations can be adapted to local conditions (Takao, 2014). The observations and evidence collected in this research highlights the significant one-way direction of policy learning (from Australia to South Africa). A key challenge for stakeholders and policy makers is then to devise ways of feeding refinements back into global policy networks and to initiating states, particularly where these refinements may strengthen the operational capacity of established policy frameworks. This research found limited evidence of the policy refinements and adjustments developed in the South African context being fed back to reshape and influence policy change in the Australian context. The Australian NHVR retains an active interest in compliance policy and the progress of the RTMS in South Africa, but to date has not made any visible changes to the NHVAS programme that reflect evidence of learning from the transfer process. So, while this case reveals a predominantly one-way transfer of policy ideas and practice, it is also recognised that policy reform and the emergence of evidence of programme change does often take time. For example, a national review of the NHVAS was initiated in 2015, and input to the consultation process included advice on what could be learned from the unique operational features of the 
RTMS (NTC, 2015). South African and Australian officials still remain actively engaged in the exchange of information and sharing of experiences, and further delegations of senior transport agency officials visited transport regulators and road agencies across Australia during 2015 (TCA, 2015: 11) Despite these opportunities for feedback and input to Australian policy processes, the evident impact of return lessons from South Africa seems yet to be realised. Where this does occur, the concept of policy transfer experience contributing to a global policy cycle of feedback and improvement will have been achieved. Of course the iterative, complex and messy nature of policy development may also mean that the observation of such sequential influence in policy systems may be unrealistic and more characteristic of an ideal model (Colebatch, 2005).

\section{CONCLUSION}

This chapter has presented a case of policy transfer across two markedly different jurisdictions. The distinctive operational differences between the NHVAS and the RTMS demonstrate the significant influence that local context plays in reshaping policy ideas and administrative frameworks as they move to implementation. The focused micro-analysis of this study has brought the detail of these differences to light. While not explicitly explored in the above analysis, this case study reveals an underlying commitment to collaboration that is also central to successful policy transfer. The ongoing engagement between South African and Australian road transport agencies reveals the existence of strong ties and a general willingness to share information and examine options on how best to shape policy to achieve common policy goals. Transfer in this case study is characterised by a willingness to look at what works best in the local context. An important challenge for policy practitioners is to then look at how improvements in practice might have application in the originating jurisdiction. While an important finding of this study is the emergence of state-to-market transfer processes, what underlies this finding is the growing importance of industry and market participants in policy transfer processes. This is important for policy transfer scholars to note, since as governments around the world increasingly look to restrain public expenditure, research may find that the process is more often shaped and guided by non-state actors than has traditionally been observed. 